\title{
Titania/mesoporous silica nanotubes with efficient photocatalytic properties
}

\author{
Krzysztof Cendrowski \\ Nanomaterials Physicochemistry Department, Faculty of Chemical Technology and Engineering, West Pomeranian \\ University of Technology, Szczecin, Al. Piastow 45, Szczecin 70-311, Poland \\ Corresponding author: kcendrowski@zut.edu.pl
}

\begin{abstract}
Ordered nanocrystalline titania-mesoporous silica nanotube structures are synthesized by hydrolysis of the titania precursor inside pours silica shell. Silica coating surrounding carbon nanotubes was further removed by thermal reduction. The proposed method of functionalization silica channels with the titania nanoparticles preclude aggregation of $\mathrm{TiO}_{2}$ nanoparticles. The nanocrystalline silica/titania $\left(\mathrm{mt}-\mathrm{SiO}_{2} / \mathrm{TiO}_{2}\right)$ nanotubes were prepared according to the describe method has high specific surface area and possesses excellent photocatalytic properties capable of decomposing phenol and methylene blue in a short time. Since the nanocrystalline $\mathrm{TiO}_{2}$ is produced in the wall of the mesoporous silica tube, phenol or dye molecules can react with $\mathrm{TiO}_{2}$ nanoparticles from both the inside and outside.
\end{abstract}

Keywords: Mesoporous silica nanotubes, silica-titania nanocomposite, photocatalysis, phenol decomposition.

\section{INTRODUCTION}

Decomposition of hazardous organic compounds in water has attracted significant attention in environmental protection ${ }^{1-3}$. Efficient cleaning of waste water is crucial to the industry and environment. However, current biological, physical, and chemical methods have several drawbacks ${ }^{3-4}$ and better techniques are required. An attractive alternative method is based on photocatalysis ${ }^{5-7}$. These methods does not produce by-products and waste being able to convert organic compounds into harmless chemicals ${ }^{3}$, and last but not least, can remove toxic, bio-resistant, and inorganic species ${ }^{4}$. Photocatalysis based on $\mathrm{TiO}_{2}$ has drawn interest due to potential applications in environmental cleaning, such as inactivation of virus in drinking water, decomposition of pollutants, solar energy conversion, and production of hydrogen energy production $^{8-14}$. Other advantages include biocompatibility, stability, and efficiency ${ }^{10-15}$. $\mathrm{TiO}_{2}$ is a wide-band gap semiconductor existing in three main crystalline phases of anatase, rutile, and brookite. The most useful titania phase for photocatalysis is anatase which can be synthesized in large quantities ${ }^{9}$. Moreover, its chemical and biological inertness, easy and economically feasible production, and photocatalytic activity render titania an ecologically friendly material. Therefore, there is increasing interest in incorporating photoactive species into different matrix materials/composites such as ceramic materials like tiles, silicates, paints and plastics to enhance the mechanical properties and surface functional properties. Photocatalytic anti-bacterial ${ }^{16,17}$, self-sterilizing ${ }^{18,19}$, self-cleaning ${ }^{20}$ and antisoiling coatings ${ }^{21}$ have been studied. Titania has a multifunctional nature. For instance, titania can form molecular hybrids with other molecules to yield good photocatalytic performance and serve as an adsorbent. Titania modified by silica $\left(\mathrm{TiO}_{2}-\mathrm{SiO}_{2}\right.$ nanocomposites) is a great candidate for mercury vapor removal. The adsorption enhancement mechanism has been investigated in details ${ }^{22-27}$. Recently, a simple technique to achieve enhanced photocatalytic activity from $\left(\mathrm{TiO}_{2}\right) \mathrm{P} 25$ titanium dioxide nanoparticles by silica addition has been reported ${ }^{11,28-30}$. Expect of the high surface are of the mesoporous silica nanoparticles, silica nanoparitcals and silica coating can be produce from the post-synthesis waste that reduce their production $\operatorname{costs}^{31}$. Silica nanocoatings and nanoparticles shows also high thermal stability and acid resistance ${ }^{32}$. Furthermore molecular hybrids based on titania can be used to clean the surface of building materials such as cement mortar, tiles, and glass panes ${ }^{30}$. $\mathrm{TiO}_{2}$-coated ceramic tiles ${ }^{\mathbf{1 4}, \mathbf{2 1}}$, sanitary ware ${ }^{34}$ and $\mathrm{TiO}_{2}$ incorporated cement are efficient in resisting organic contaminants, inorganic materials, as well as bacteria. The use of these materials in hospitals and health care facilities such as public comfort stations can reduce the spread of infection and threat to patients, especially those whose immune systems are weak. Moreover, it has been shown that Amphotericin B covalently attached to silica nanoparticles exhibits effective antifungal properties $^{35}$. Therefore, surfaces coated with these antifungal nanoparticle conjugates have large potential in medical devices requiring antifungal properties. However, covalent functionalization can be easily destroyed via cleavage of chemical bonds and more stable materials are desired. In this work, a novel molecular hybrid combining the large surface area of silica with the photocatalytic properties of titania is investigated. It is composed of mesoporous silica nanotubes with channels filled by anatase titania $(\sim 25$ wt.\%). This structure improves the photocatalytic efficiency of $\mathrm{TiO}_{2}$ in the ultraviolet light region relative to P25 titanium dioxide nanoparticles.

\section{EXPERIMENTAL SECTION}

\section{Materials}

Carbon nanotubes used to synthesis of mesoporous shell were purchased from Shenzhen Nanotech Port Co. (Shenzhen, China). Silica (tetraethyl orthosilicate - TEOS) and titania precursor (Titanium(IV) butoxide - TBT) was purchased from Sigma-Aldrich. Ethanol and n-propanol were provided from Chempure (Poland, Piekary Sląskie) and from Polskie Odczynniki Chemiczne - POCH S.A. (Poland, Gliwice).

Synthesis of silica nanotubes with titania in the mesoporous channels $\left(\mathrm{mt}-\mathrm{SiO}_{2} / \mathrm{TiO}_{2}\right)$

To fabricate a thin mesoporous silica layer $(30 \mathrm{~nm})$, $0.2 \mathrm{~g}$ of multiple wall carbon nanotubes were dis- 
persed ultrasonically in a solution containing $0.3 \mathrm{~g}$ of hexadecyl(trimethyl)azanium bromide (CTAB), $1.0 \mathrm{~g}$ of $\mathrm{NH}_{3} \cdot \mathrm{H}_{2} \mathrm{O}, 60 \mathrm{ml}$ of ethanol, and $80 \mathrm{ml}$ of deionized water $\left(\mathrm{H}_{2} \mathrm{O}\right)$. The mixture was stirred for $18 \mathrm{~h}$ at room temperature after addition of $0.4 \mathrm{~g}$ tetraethyl orthosilicate (TEOS) as the silica precursor. The suspension was centrifuged at $8000 \mathrm{rpm}$ for 20 minutes and thoroughly washed with ethanol. After removing the suspension residues, $\mathrm{CTAB}$ was evaporated from the silica-carbon nanotubes in air at $400^{\circ} \mathrm{C}$ for 2 hours. The mesoporous silica-carbon nanotubes were sonicated for 3 hours in 5 $\mathrm{ml}$ of concentrated tetrabutyl titanate (TBT). Afterwards, the TBT and silica-carbon nanomaterials were diluted with n-propanol and collected after centrifugation at $8000 \mathrm{rpm}$ for 30 minutes. To remove excess TBT, the sample was washed several times with n-propanol and then dispersed in ethanol to hydrolyse the titanium dioxide precursor. The mesoporous silica nanotubes with titania were obtained after calcination at $600^{\circ} \mathrm{C}$ for four hours to remove the CNT core and convert the titanium dioxide to the anatase phase.

\section{Determination of photocatalytic activity}

The photocatalytic activity of the $\mathrm{mt}-\mathrm{SiO}_{2} / \mathrm{TiO}_{2}$ and P-25 (control) samples was examined by the decomposition of phenol and methylene blue. The reaction was carried out in an inner-irradiation-type reactor with a mercury lamp $(150 \mathrm{~W})$ as the ultra-violet light source. In the photocatalytic reaction, $700 \mathrm{~cm}^{3}$ of a phenol or methylene blue solution (initial concentration: $50 \mathrm{mg} /$ $\mathrm{dm}^{3}$ ) with $50 \mathrm{mg}$ of the catalyst was used. After 30 minutes of adsorption in darkness, the reaction mixture was irradiated. Nominal doses of the reaction mixtures were extracted at regular time intervals to determine the phenol/methylene blue concentration in the solution. The phenol/methylene blue concentration was determined by the diffuse reflectance (DR) UV-Vis technique on the Jasco V-650 spectrophotometer (Jasco, Japan).

\section{RESULTS}

\section{Nanomaterials characterization}

Figure 1 shows the high-resolution transmission electron microscopy (TEM) images revealing morphological changes on the samples. The TEM images show that the surface of the multiple wall carbon nanotubes is covered by the mesoporous silica shell with an average diameter of $30 \mathrm{~nm}$ (Fig. $1 \mathrm{a}$ and a'). The elemental composition, determined by the EDS mapping proves the successful mesoporous silica coating (Fig. 1 a"). In respect to the figure $1 \mathrm{a}$ and a', both high-resolution TEM images in the figures $1 \mathrm{~b}$ and $\mathrm{b}$ ' reveal the presence of an additional structure in the channels of the mesoporous silica after filling with titanium dioxide. The mesoporous layer cannot be seen clearly from this sample. The bamboo like structure in the carbon nanotubes blocks the introduction of titania in the inner space of the nanotubes. In order to confirm the filling effect efficacy, EDS mapping was performed and the results are depicted in Figure b". In the mapping images red, yellow and green colors corresponds respectively to carbon, silica and titanium. From the comparison of the images clearly see that the hollow space in the signal coming from the outer mesoporous silica shell, attributes to the red signal from the CNT. The green signal coming from titanium contains in the mesoporous silica. For further verification of the morphological modification, the surface area is measured based on the $\mathrm{N}_{2}$ adsorption isotherm. The surface area of CNT- $\mathrm{mSiO}_{2}-\mathrm{TiO}_{2}$ is $152 \mathrm{~m}^{2} / \mathrm{g}$ and $\mathrm{CNT}-\mathrm{mSiO}_{2}$ has a surface area of $894 \mathrm{~m}^{2} / \mathrm{g}$. It means that the surface of CNT-mSiO $-\mathrm{TiO}_{2}$ decreases by a factor of six compared to the starting materials due to filling of the channels in the mesoporous silica by titania. The CNT- $\mathrm{mSiO}_{2}-\mathrm{TiO}_{2}$ is annealed in air at $600^{\circ} \mathrm{C}$ to form anatase phase of titanium dioxide and remove carbon nanotubes in order to exonerate the inner space. Figures $1 \mathrm{c}$ and c' show the tubular structures without carbon nanotubes inside. However, the outer surface is unchanged with respect to $\mathrm{CNT}-\mathrm{mSiO}_{2}-\mathrm{TiO}_{2}$. The efficiency of carbon nanotube removal is confirmed by EDS mapping (see Figure 1 c"). The TEM and EDS study does not show any CNTs and removal of carbon nanotubes increases the specific surface area of this sample to $234 \mathrm{~m}^{2} / \mathrm{g}$.

Raman scattering spectra are acquired to determine presence of individual elements in the nanomaterials using a laser beam with an excitation wavelength of 785 $\mathrm{nm}$. Figure 2 depicts the spectrum of three different nanostructures, two immediate nanostructures formed during the synthesis as well as the final product. The spectra of the both the CNT and $\mathrm{mSiO}_{2} / \mathrm{CNT} / \mathrm{TiO}_{2}$ exhibit two strong peaks associated with the $\mathrm{G}$ and $\mathrm{D}$ modes. The intensity of the CNT modes is weak during the synthesis. In the final product ( $\mathrm{mt}-\mathrm{SiO}_{2} / \mathrm{TiO}_{2}$ ) after CNT removal, peaks from the $\mathrm{G}$ and $\mathrm{D}$ modes diminish towards the intensity of the lower frequency region peaks (100-650 $\mathrm{cm}^{-1}$ ) corresponding to silica (green line) and titania (blue line). Sharp peaks appearing after annealing at 146 $\mathrm{cm}^{-1}, 396 \mathrm{~cm}^{-1}, 520 \mathrm{~cm}^{-1}, 630 \mathrm{~cm}^{-1}$ can be attributed to phonon modes of anatasa ${ }^{38}$ verifying the anatase phase presence. However, lack of the D and G bands of CNT provides evidence that annealing removes the template completely. The X-ray diffraction (XRD) pattern of the $\mathrm{mT}-\mathrm{SiO}_{2} / \mathrm{TiO}_{2}$ which confirms the presented studies was reported previously ${ }^{39}$. The majority of the diffraction peaks was indexed to the pure tetragonal anatase phase (ICDD \#00 021 1272) of highly UV-light active titania. In the range of 15 to 30 degrees, the broad peak corresponds to silica in the nanomaterials. Peaks marked in the spectrum corroborates the high efficiency in the fabrication of mesoporous silica nanotubes with titanium dioxide. Mean diameter of the commercial $\mathrm{TiO}_{2}-\mathrm{P} 25$ (Aeroxide) particles was $22 \mathrm{~nm}$, with the specific surface area ranging from 35 to $56 \mathrm{~m}^{2} / \mathrm{g}$. The XRD measurements showing phase mixture (anatase and rutile) of the P25 nanoparticles are presented in the previous report ${ }^{11}$.

\section{Photocatalytic activity}

The photocatalytic performance of the materials were evaluated using UV light by a phenol decomposition reaction with respect to the same amount of the commercial catalyst P25. Figure 3 illustrates the dependence of the phenol concentration to reaction time on the mt$\mathrm{SiO}_{2} / \mathrm{TiO}_{2}$ nanotubes (cubes), P25 (triangle) and without catalyst (circle). The results indicate that the synthesized $\mathrm{mt}-\mathrm{SiO}_{2} / \mathrm{TiO}_{2}$ is photocatalytically active in phenol de- 

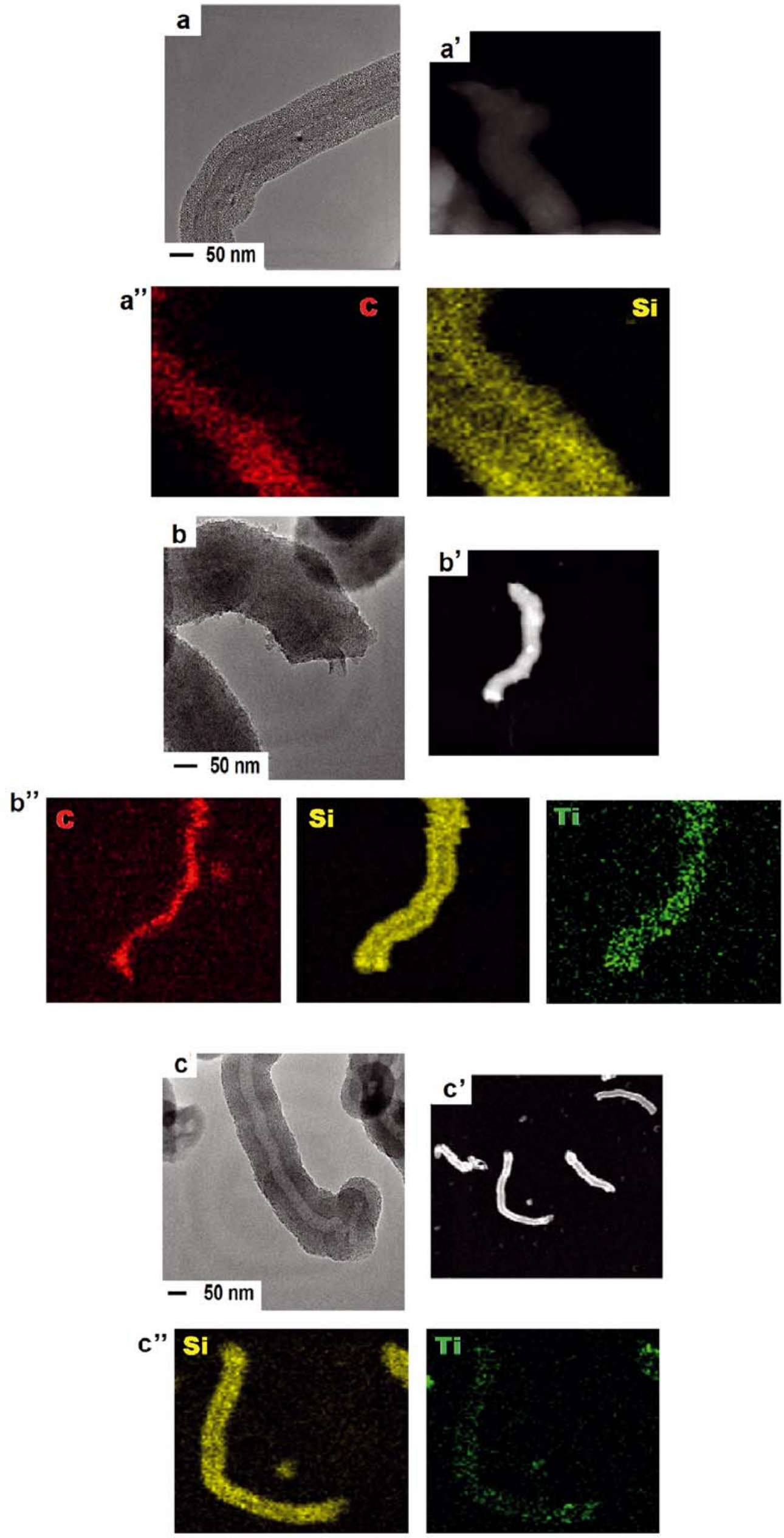

Figure 1. EDS elemental mapping (a, b, c) supplemented with TEM (a,b,c) and STEM (a, b, c) images of mesoporous silica-carbon nanotubes, carbon-silica-titania nanotubes and mesoporous silica-titania nanotubes, respectively 


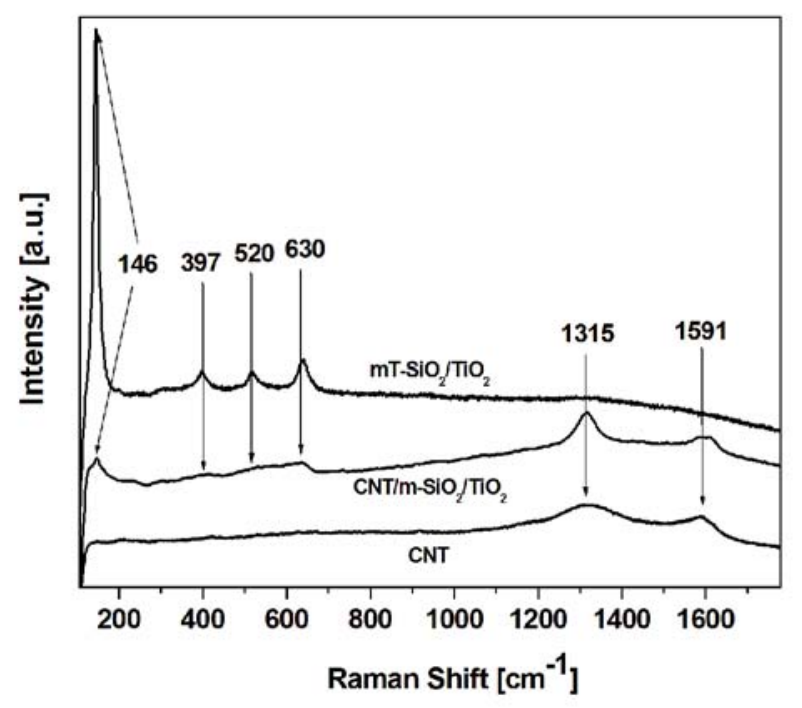

Figure 2. Raman spectra of carbon nanotubes (CNT), mesoporous silica/carbon nanotubes supported with titania $\left(\mathrm{CNT} / \mathrm{m}-\mathrm{SiO}_{2} / \mathrm{TiO}_{2}\right)$ and mesoporous silica nanotubes with titania $\left(\mathrm{mt} \mathrm{SiO}_{2} / \mathrm{TiO}_{2}\right)$

composition and the performance is much better than that of the commercial catalyst. For example, after 30 minutes of UV irradiation, $76 \%$ of the phenol is by mt-SiO$/ 2 / \mathrm{TiO}_{2}$ and $24 \%$ by $\mathrm{TiO}_{2}$-Degussa P25. After 120 minutes, $99 \%$ of the phenol is decomposed by $\mathrm{mt}-\mathrm{SiO}_{2} /$ $\mathrm{TiO}_{2}$ and only $60 \%$ by $\mathrm{TiO}_{2}$-Degussa P25.

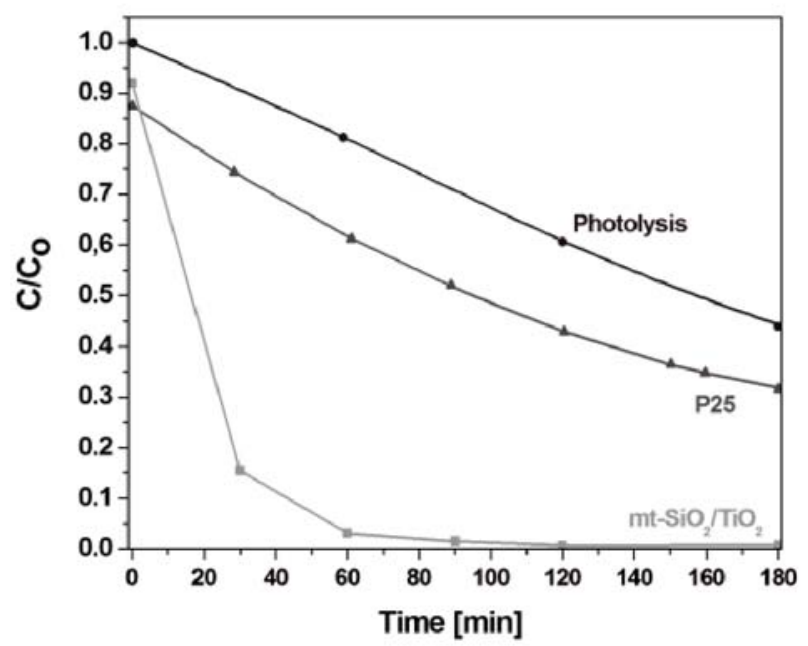

Figure 3. Photocatalytic decomposition of phenol by mesoporous silica nanotubes with titanium dioxide $\mathrm{mt}-\mathrm{SiO}_{2} / \mathrm{TiO}_{2}$ and P-25 catalyst under UV light

In order to confirm the high photocatalytic performance of the $\mathrm{mt}-\mathrm{SiO}_{2} / \mathrm{TiO}_{2}$, dye (methylene blue) decomposition under UV light was evaluated. The reaction was carried out with respect to same amount of the the commercial catalyst P25. Figure 4 illustrates the dependence of the dye concentration to reaction time on the $\mathrm{mt}-\mathrm{SiO}_{2} / \mathrm{TiO}_{2}$ nanotubes (cubes), P25 (triangle) and without catalyst (circle). The results confirmed that the synthesized mt-SiO $2 / \mathrm{TiO}_{2}$ is highly photocatalytically active and the performance is better than that of the commercial catalyst. After 20 minutes of UV irradiation, $95 \%$ of the dye is decomposed by $\mathrm{mt}-\mathrm{SiO}_{2} / \mathrm{TiO}_{2}$ and $80 \%$ by $\mathrm{TiO}_{2}$-Degussa P25.

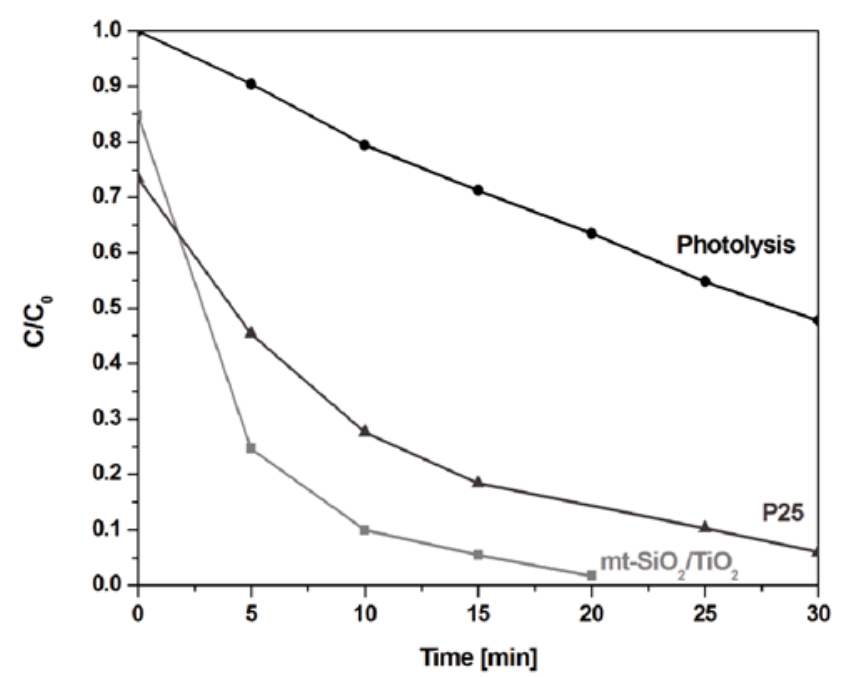

Figure 4. Photocatalytic decomposition of methylene blue by mesoporous silica nanotubes with titanium dioxide $\mathrm{mt}-\mathrm{SiO}_{2} / \mathrm{TiO}_{2}$ and $\mathrm{P}-25$ catalyst under UV light

The $\mathrm{mt}-\mathrm{SiO}_{2} / \mathrm{TiO}_{2}$ after the reaction did not reveal any changes in the structure of nanoparticles. Post the reaction, $\mathrm{mt}-\mathrm{SiO}_{2} / \mathrm{TiO}_{2}$ shows similar tubular structure (Figure $5 \mathrm{~b}-\mathrm{c}$ ) as the pristine photocatalyst (Fig. 5a). The photocatalyst chemical structure after phenol decomposition is comparable to pristine catalyst (Fig. 5d). XRD spectrum of the $\mathrm{mt}-\mathrm{SiO}_{2} / \mathrm{TiO}_{2}$ before and after photocatalytic decomposition of phenol shows the same peaks assigned to the anatase phase (marked - A) and silica (broad peak marked $-\mathrm{SiO}_{2}$ ).

\section{DISCUSSION}

In this contribution nanocrystalline $\mathrm{TiO}_{2}$ has been successfully prepared in wall of mesoporous silica tubes through the simple and efficient methodology. $\mathrm{TiO}_{2}$ precursor supported in the silica nanochannels was transformed into crystallized $\mathrm{TiO}_{2}$ nanoparticles through hydrolysis and further by high temperature treatment. The direct formation of the $\mathrm{TiO}_{2}$ nanoparticles in side of silica channels inhibited the agglomeration of $\mathrm{TiO}_{2}$ particles ${ }^{39}$. The obtained nanocrystalline $\mathrm{TiO}_{2}$ supported in the wall of mesoporous silica tubes also showed the high specific surface area due to the presence of tubular and mesoporous structure. These characters enable the $\mathrm{mt}-\mathrm{SiO}_{2} / \mathrm{TiO}_{2}$ nanotubes to exhibit enhancement properties in photocatalytic decomposition of phenol and methylene blue. In photocatalytic decomposition of phenol in water, phenol was completely decomposed in very short time under UV light. Therefore together with bactericidal properties ${ }^{39}$ it shows great advantage in respect to $\mathrm{P} 25$. This can be attributed to the fact that the nanocrystalline $\mathrm{TiO}_{2}$ was supported in the wall of mesoporous silica tube and phenol molecules can react with $\mathrm{TiO}_{2}$ from both sides: outside and inside of the silica tube, increasing the reaction rate dramatically. The high specific surface area also enhance the photoactivity of the prepared molecular system. Thus this method provides an easy way to treat the polluted water and great potential application in food or cosmetics industry.

Previous results of the anti-bacterial activity of the mt- $\mathrm{SiO}_{2} / \mathrm{TiO}_{2}$ on Escherichia coli (ATCC 25922) clearly shows advantage in the microorganism growth inhibi- 

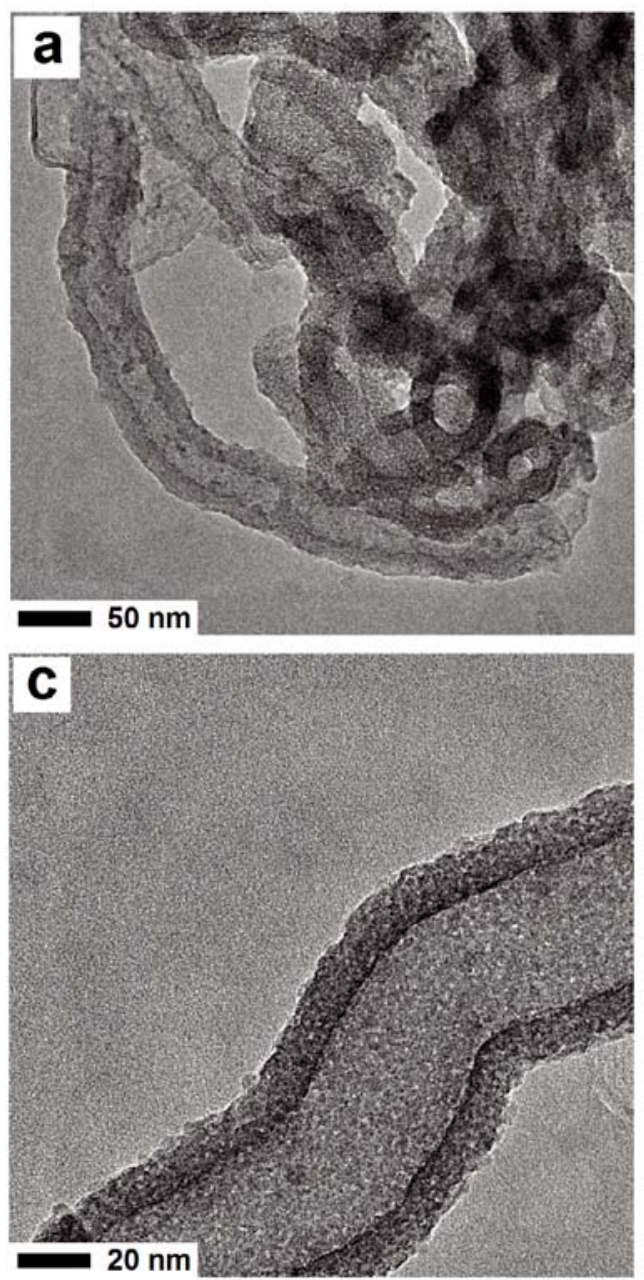
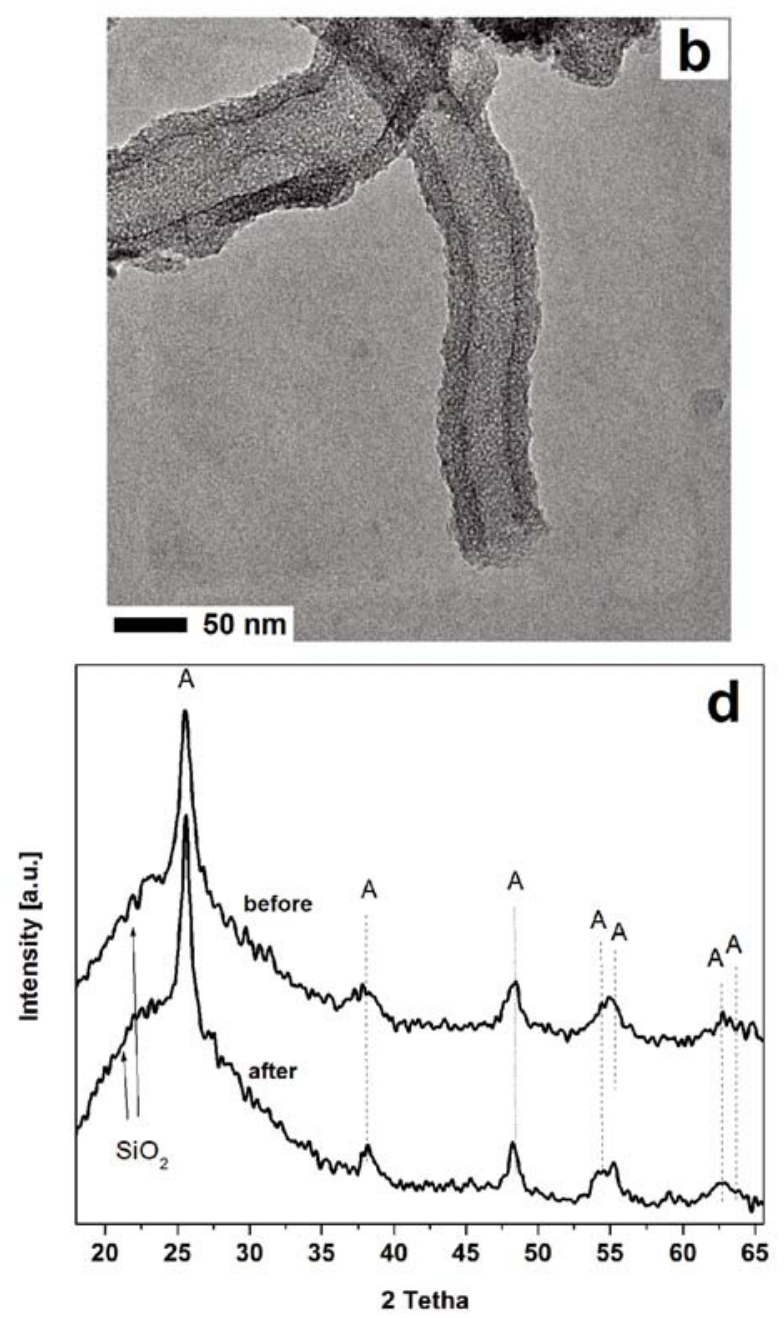

Figure 5. TEM images of mesoporous silica nanotubes with titanium dioxide $\mathrm{mt}-\mathrm{SiO}_{2} / \mathrm{TiO}_{2}$ nanotubes before (a) and after (b, c) phenol decomposition. XRD spectrum (d) of the nanotubes before and after phenol decomposition

tion, compared to commercial $\mathrm{TiO}_{2}{ }^{39}$. The mesoporous nanotubes with titania completely inhibit the Escherichia coli after UV-light treatment (required two time less time then commercial titanium dioxide). Previous study on the biocompatibility of this nanostructure with mouse fibroblast cells L929 ${ }^{39}$ showed that above $100 \mu \mathrm{g} /$ $\mathrm{mL}$ concentration nanomaterials starts exhibiting weak toxicity effect. Therefore high biocompatibility, bactericidal and photocatalytic performance of the $\mathrm{mt}-\mathrm{SiO}_{2} /$ $\mathrm{TiO}_{2}{ }^{11,39}$ shows that this structure has great potential in the future applications.

\section{CONCLUSIONS}

Concluding, we have successfully fabricated uniform molecular hybrid based on mesoporous silica nanotubes with channels filled with nanocrystalline titanium dioxide in a anatase phase. Novel nanomaterial exhibits high surface area with high purity - free from titania impurities. The photocatalytic activity of this structure was significantly increased due to the dramatically enhanced reaction rate in respect to the commercial catalyst. Proposed photocatalyst is chemically stable during the reaction and maintains its morphology. The presented photoactive system paves the way for the development of a new generation of water purification system. Future investigations will focus on the detailed antibacterial, antifungal and photocatalytic efficiency in different environmental conditions of this material.

\section{LITERATURE CITED}

1. Carp, O., Huisman, C.L. \& Reller, A. (2004) Photoinduced reactivity of titanium dioxide. Solid State Chem. 32, 33-177. DOI: 10.1016/j.progsolidstchem.2004.08.001.

2. Ma, Y. \& Yao, J.N. (1998) Photodegradation of Rhodamine $\mathrm{B}$ catalyzed by $\mathrm{TiO}_{2}$ thin films. J. Photochem. Photobiol. A 116, 167-170. DOI: 10.1016/S1010-6030(98)00295-0.

3. Stylidi, M., Kondarides, D.I. \& Verykios, X.E. (2003) Pathways of solar light-induced photocatalytic degradation of azo dyes in aqueous $\mathrm{TiO}_{2}$ suspensions. Appl. Catal. B 40, 271-286. DOI: 10.1016/S0926-3373(02)00163-7.

4. Chen, D. \& Ray, A.K. (2001) Removal of toxic metal ions from wastewater by semiconductor photocatalysis. Chem. Eng. Sci. 56, 1561-1570. DOI: 10.1016/S0009-2509(00)00383-3.

5. Khenniche, L., Favier, L., Bouzaza, A., Fourcade, F., Aissani, F. \& Amrane, A. (2015) Photocatalytic degradation of bezacryl yellow in batch reactors-feasibility of the combination of photocatalysis and a biological treatment. Environ. Technol. 36(1), 1-10. DOI: 10.1080/09593330.2014.934740.

6. Favier, L., Ionut Simion, A., Rusu, L., Pacala, M.L., Grigoras, C. \& Bouzaza, A. (2015) Removal of an Organic Refractory Compound by Photocatalysis in Batch Reactor-Kinetic Studies. Environ. Eng. Manag. J. 14(6), 1327-1338.

7. Favier, L., Simion, A.I., Matei, E., Grigoras, C.G., Kadmi, Y. \& Bouzaza, A. (2016). Photocatalytic oxidation of a hazardous phenolic compound over $\mathrm{TiO}_{2}$ in a batch system. Environ. Eng. Manag. J. 15, 5, 1059-1067. 
8. Kitano, M., Matsuoka, M., Ueshima, M. \& Anpo, M. (2007) Recent developments in titanium oxide-based photocatalysts. Appl. Catal. A. 325, 1-14. DOI: 10.1016/j.apcata.2007.03.013.

9. Fujishima, A., Zhang, X.T. \& Tryk, D.A. (2008) $\mathrm{TiO}_{2}$ photocatalysis and related surface phenomena. Surf. Sci. Rep. 63(12), 515-582. DOI: 10.1016/j.surfrep.2008.10.001.

10. Asahi, R., Morikawa, T., Ohwaki, T., Aoki, K. \& Taga, Y. (2001) Visible-Light Photocatalysis in Nitrogen-Doped Titanium Oxides. Science. 293, 269-271. DOI: 10.1126/science.1061051.

11. Cendrowski, K., Chen, X., Zielinska, B., Kalenczuk, R.J., Rümmeli, M.H., Büchner, B.R., Klingeler \& Borowiak-Palen, E. (2011) Synthesis, characterization, and photocatalytic properties of core/shell mesoporous silica nanospheres supporting nanocrystalline titania J. Nanopart. Res. 11051/NANO, 307(13), 5899-5908. DOI: 10.1007/s11051-011-0307-1.

12. Hoffmann, M.R., Martin, S.T., Choi, W. \& Bahnemann, D.W. (1995) Environmental Applications of Semiconductor Photocatalysis. Chem. Rev. 95, 69-96. DOI: 10.1021/cr00033a004.

13. Khan, S.U.M., Al-Shahry, M. \& Ingler, W.B. (2002) Efficient photochemical water splitting by a chemically modified n-TiO 2 . Science. 297, 2243-2245. DOI: 10.1126/science.1075035.

14. Sikora, P., Augustyniak, A., Cendrowski, K., Horszczaruk, E., Rucinska, T., Nawrotek, P. \& Mijowska, E. (2016) Characterization of mechanical and bactericidal properties of cement mortars containing waste glass aggregate and nanomaterials. Materials 9, 701, 1-16. DOI: 10.3390/ma9080701.

15. Vinodgopal, K., Wynkoop, D.E. \& Kamat, P.V. (1996) Environmental photochemistry on semiconductor surfaces: Photosensitized degradation of a textile azo dye, acid orange 7, on $\mathrm{TiO}_{2}$ particles using visible light. Environ. Sci. Technol. 30(5), 1660-1666. DOI: 10.1021/es950655d.

16. Hu, C., Lan, Y., Qu, J., Hu, X. \& Wang, A. (2006) Ag/ $\mathrm{AgBr} / \mathrm{TiO} 2$ Visible Light Photocatalyst for Destruction of Azodyes and Bacteria. J. Phys. Chem. B. 110(9), 4066-4072. DOI: $10.1021 /$ jp0564400.

17. Rao, K.V.S., Zhuo, B., Cox, J.M., Chiang, K., Brungs, M. \& Amal, R. (2006) Photoinduced Bactericidal Properties of Nanocrystalline TiO2 Thin Films. J. Biomed. Nanotechnol. 2, 71-73. DOI: 10.1166/jbn.2006.006.

18. Kikuchi, Y., Sunada, K., Iyoda, T., Hashimoto, K. \& Fujishima, A. (1997) Photocatalytic bactericidal effect of TiO2 thin films: dynamic view of the active oxygen species responsible for the effect. J. Photochem. Photobiol. A: Chem. 106, 51-56. DOI: 10.1016/S1010-6030(97)00038-5.

19. Sunada, K., Kikuchi, Y., Hashimoto, K. \& Fujishima, A. (1998) Bactericidal and Detoxification Effects of $\mathrm{TiO}_{2}$ Thin Film Photocatalysts. Environ. Sci. Technol. 32, 726-728. DOI: 10.1021/es970860o.

20. Parkin, I.P. \& Palgrave, R.G. (2005) Self-cleaning coatings. J. Mater. Chem. 15, 1689-1695. DOI: 10.1039/B412803F

21. Fujishima, A., Rao, T.N. \& Tryk, D.A. (2001) Titanium dioxide photocatalysis. J. Photochem. Photobiol. C: Photochem. Rev. 1, 1-21. DOI: 10.1016/S1389-5567(00)00002-2.

22. Pitoniak, E., Wu, C.Y., Londeree, D., Mazyck, D., Bonzongo, J.C., Powers, K. \& Sigmund, W. (2003) Nanostructured silica-gel doped with $\mathrm{TiO} 2$ for mercury vapor control. J. Nanopart. Res. 5, 281-292. DOI: 10.1023/A:1025582731470.

23. Wu, C.Y., Lee, T.G., Tyree, G., Arar, E. \& Biswas, P. (1998) Capture of Mercury in Combustion Systems by In Situ-Generated Titania Particles with UV Irradiation. Environ. Eng. Sci. 15, 137-148. DOI: 10.1089/ees.1998.15.137.

24. Li, Y., Murphy, P. \& Wu, C.Y. (2008) Removal of elemental mercury from simulated coal-combustion flue gas using a SiO2-TiO2 nanocomposite. Fuel Process. Technol. 89, 567-573. DOI: 10.1016/j.fuproc.2007.10.009.

25. Li, Y. \& Wu, C.Y. (2007) Kinetic Study for Photocatalytic Oxidation of Elemental Mercury on a SiO2-TiO2 Nanocomposite. Environ. Eng. Sci. 24(1), 3-12. DOI: 10.1089/ees.2007.24.3.

26. Li, Y. \& Wu, C.Y. (2006) Role of moisture in adsorption, photocatalytic oxidation, and reemission of elemental mercury on a SiO2-TiO2 nanocomposite. Environ. Sci. Technol. 40(20), 6444-6448. DOI: 10.1021/es061228a.

27. Pitoniak, E., Wu, C.Y., Mazyck, D.W. \& Powers, K.W. (2005) Adsorption Enhancement Mechanisms of Silica-Titania Nanocomposites for Elemental Mercury Vapor Removal. Environ. Sci. Technol. 39, 1269-1274. DOI: 10.1021/es049202b.

28. Huma, R.J., Michael, V.L., Li, Q. \& Barron, A.R. (2011) Simple Route to Enhanced Photocatalytic Activity of P25 Titanium Dioxide Nanoparticles by Silica Addition. Environ. Sci. Technol. 45(4), 1563-1568. DOI: 10.1021/es102749e.

29. Fox, M.A. \& Dulay, M.T. (1993) Heterogeneous photocatalysis. Chem. Rev. 93, 341-357. DOI: 10.1021/cr00017a016.

30. Augustyniak, A., Cendrowski, K., Nawrotek, P., Barylak, M. \& Mijowska. E. (2016) Investigating the interaction between Streptomyces sp. and titania/silica nanospheres. Water, Air, \& Soil Pollut. 227, 230, 1-13. DOI: 10.1007/s11270-016-2922-z.

31. Cendrowski, K., Sikora, P., Horszczaruk, E. \& Mijowska, E. (2017) Waste-free synthesis of silica nanospheres and silica nanocoatings from recycled ethanol-ammonium solution. Chem. Papers 71, 841-848. DOI: 10.1007/s11696-016-0099-y.

32. Cendrowski, K., Sikora, P., Zielinska, B., Horszczaruk, E. \& Mijowska, E. (2017) Chemical and thermal stability of the core-shelled magnetite nanoparticles with solid silica. Appl. Surf. Sci. 407, 391-397. DOI: 10.1016/j.apsusc.2017.02.118

33. Sikora, P., Cendrowski, K., Markowska-Szczupak, A., Horszczaruk, E. \& Mijowska, E. (2017) The effects of silica/ titania nanocomposite on the mechanical and bactericidal properties of cement mortars. Constr. Build. Mater. 150, 738-746. DOI: 10.1016/j.conbuildmat.2017.06.054.

34. Machinda, M., Norimoto, W.K. \& Kimura, T. (2005) Antibacterial Activity of Photocatalytic Titanium Dioxide Thin Films with Photodeposited Silver on the Surface of Sanitary Ware. J. Am. Ceram. Soc. 88(1), 95-100. DOI: 10.1111/j.1551-2916.2004.00006.x.

35. Paulo, S.O.C., Vidal, M. \& Ferreir, L.S. (2010) Antifungal Nanoparticles and Surfaces. Biomacromolecules 11, 2810-2817. DOI: $10.1021 / \mathrm{bm} 100893 \mathrm{r}$.

38. Li, M., Hong, Z., Fang, Y. \& Huang, F. (2008) Synergistic effect of two surface complexes in enhancing visible-light photocatalytic activity of titanium dioxide. Mater. Res. Bull. 43, 2179-2186. DOI: 10.1016/j.materresbull.2007.08.030.

39. Cendrowski, K., Peruzynska, M., Markowska-Szczupak, A., Chen, X., Wajda, A., Lapczuk, J., Kurzawski, M., Kalenczuk, R.J., Drozdzik, M. \& Mijowska, E. (2014) Antibacterial performance of nanocrystallined titania confined in mesoporous silica nanotubes. Biomed Microdevices. 16 (3), 449-458. DOI: 10.1007/s10544-014-9847-3. 